\title{
LEX EX MACHINA: REASONS FOR ALGORITHMIC REGULATION ${ }^{*}$
}

\author{
by \\ MIRKO PEČARIČ $\check{C}^{* *}$
}

A major unanswered question in regulation concerns the application of cognitive diversity and various data as inputs for the creation of general legal rules. The paper claims this diversity can be assured with the help of algorithmic planning. Classical regulation is hence put under question due to its inability to quickly adapt to changing conditions, where relations per se change also intentions, tools and goals. The paper proposes two paths towards a computational simulation of legal situations: with the help of algorithms that can ensure the needed adaptability and relevancy of hidden data correlations, and with collective intelligence based on human inputs where data for algorithms is not available. The aim of this work is to extend the pre-regulatory practice of extracting information from data with the help of algorithms to determine patterns and predict future results and trends (written now as general legal rules). Nowadays, algorithms could be used at least as advice, especially in a prepreparation, draft phase of legal acts.

\section{KEY WORDS}

Planning, Anticipation, Adaptive Legislation, Autopilot, Stochastic Indicators, Algorithm

\footnotetext{
The author gratefully acknowledges the financial support of the Slovenian Research Agency, Grant No. J5-7557 (Transformation of governance and public service delivery mechanisms in the digital age).

** Mirko Pečarič, Professor of administrative law and public administration. University of Ljubljana, Faculty of Administration, Gosarjeva ulica 5, 1000 Ljubljana, Slovenia. E-mail: mirko.pecaric@fu.uni-lj.si
} 


\section{INTRODUCTION}

"A plan of action is the chief manifestation of planning and is, at one and the same time, the result envisaged, the line of action to be followed, the stages to go through, and methods to use."1

One amongst must-read books for legal practitioners is Bingham's The Rule of Law;' its first principle is: 'the law must be accessible and so far as possible intelligible, clear and predictable' (emphasis added). Indeed, for Fayol, as the founder of scientific management, planning is the first element of management (then follows organising, command, coordination and control): to foresee, means to assess the future and make provision for it. $^{3}$ Also in Gulick's well-known POSDCORB acronym planning stands as the first task for the chief executive (Planning, Organizing, Staffing, Directing, Coordinating, Reporting and Budgeting). ${ }^{4}$ People plan many things: inflation, GDP, unemployment, expenses, profitability, one's retirement, vacations, the time required to complete projects, etc. When the meaning of planning as the establishment of goals, policies, and procedures for a social or economic unit' ${ }^{5}$ is applied to a general legal act (a statute), the term's inadequacy is exposed: predictability in planning is achieved with more specific arrangements (adjustments of fit among things), while legislation does this with general words (with demands for justice, a la French liberté, égalité, fraternité). The first is the logic of action, the second of justification. Prediction or foreseeability is in law enabled mainly by the fundamental legal principles (to know how to act/decide), and it is important also for (tort) liability (to know how not to [even un-] intentionally harm).

1 Fayol, H. (1954) General and Industrial Management. London: Sir Isaac Pitman \& Sons, Ltd., p. 43.

2 Bingham, T. (2011) The Rule of Law. London: Penguin UK.

3 Fayol, H. (1954) General and Industrial Management. London: Sir Isaac Pitman \& Sons, Ltd., p. 48.

4 Gulick, L. (2003) Notes on the Theory of Organisation. In: Kenneth Thompson, Luther Gulick, Lyndall Urwick (eds.) New York and London: Routledge. With planning, the wellknown terms of vision (a company's main purposes by focusing on the future), mission (a vision expressed in practical terms) and strategy (ways to use the mission statement in order to achieve the vision statement through the short- and long-term goals, timelines, indicators of success, action plans) are connected. In legal terms, vision resembles a constitution, mission to statutes and bylaws to strategies, but these legal terms are not close to planning (even when national programmes (strategies) are included), although the law with its anticipative, ex ante element should exhibit it.

5 Merriam-Webster (2020) Definition of Planning by Merriam-Webster. Available from: https://www.dictionary.com/browse/planning [Accessed 24 October 2020]. 
So, the question is how is planning as the first element of scientific management present in the law, how is it reflected in action, in real legal effect, that should 'realise the public interest by doing good', as the impetus and legitimation for planning ${ }^{6}$ Up to the present time, morality and ethics provided this anticipative, general (although not specific enough, but nevertheless satisficing) element of goodness in legislation, ${ }^{7}$ mainly in the form of general legal principles as linguistic points extracted from past examples that cannot exactly show conditions, under which results can be later reached: they give only a frame (in which possible results are allowed) and weight, ${ }^{8}$ by which things are balanced. Principles are applied on specific contexts, which are per se detached from the future's pain, pleasure, virtue or values, and thus leave a room to (a human's subjective) interpretation of officials in the Executive and Judicial branch of power, who still decide mainly on intuition ${ }^{9}$ and 'rational' common sense. ${ }^{10}$ Practice rarely uses the actuarial tables, precise calculations or explicit analysis of best results from similar occasions. It uses language, but also here

6 Lennon, M. (2020) Planning as Justification. Planning Theory \& Practice, 1-5.

7 A lawmaker's judgment is not on a particular case but about what lies in the future and in general: 'this is why it is necessary to have the introduction or the narration and each of the other parts; for [in treating these matters] they concern themselves only with how they may put the judge in a certain frame of mind, while they explain nothing about artistic [logical] proofs' (Aristotle, (2007) On Rhetoric: A Theory of Civic Discourse. New York: OUP, pp. 32-33. Aristotelian recommendation is directly reflected in Article 296 of TFEU: "legal acts shall state the reasons on which they are based and shall refer to any proposals, initiatives, recommendations, requests or opinions". For Cicero law is the right reason enjoying what is good and forbidding what is evil, where the true basis of justice is to love mankind, and not utility. Cicero, M.T. (1853) The Treatises of M.T. Cicero: On the Nature of the Gods; On Divination; On Fate; On the Republic; On the Laws; and On Standing for the Consulship. London: H. G. Bohn. On the other hand, Bentham's utility principle of the greatest happiness of the greatest number replaces right reason with individuals' pleasures. Bentham, J. (1843) The Works of Jeremy Bentham, Principles of Morals and Legislation, Fragment on Government, Civil Code, Penal Law. Edinburgh: William Tait. Such stance is unsolvable when priorities and justice and/or needs and interests are in conflict. Fukuyama, F. (2002) Our Posthuman Future - Consequences of the Biotechnology Revolution. New York: Farrar, Strauss and Giroux. The majority of the stupid is invincible and guaranteed for all time. The terror of their tyranny, however, is alleviated by their lack of consistency. Einstein, A. (1960) Ideas and Opinions. New York: Crown Publishers. Adam Smith's never finished intention was to establish 'a theory of the general principles which ought to run through and be the foundation of the laws of all nations'. Smith, A. (1984) The Theory of Moral Sentiments. Indianapolis: Liberty Fund, p. 341.

8 When principles intersect...one who must resolve the conflict has to take into account the relative weight of each. Dworkin, R. (1978) Taking Rights Seriously. Cambridge: Harvard University Press, pp. 24, 27.

9 Intuition cannot be trusted in the absence of stable irregularities in the environment. Kahneman, D. (2013) Thinking, Fast and Slow. New York: Farrar, Straus and Giroux, p. 241.

10 Under these [situations that exhibit complexity, different from everyday situations] circumstances, common sense turns out to suffer from a number of errors that systematically mislead us. Yet because of the way we learn from experience...the failings of common-sense reasoning are rarely apparent to us. Watts, D.J. (2011) Everything Is Obvious: *Once You Know the Answer. New York: Crown Publishing Group, p. viii. 
the Watson's IBM computing system in 2011 won against the world's best Jeopardy! champions ${ }^{11}$ and thus took over the monopoly not only over logic but also over natural language - in which legal provisions are written.

Nowadays, the calculations of large and various data sets (that hide/show patterns and correlations) are made by computing power and different software applications to make informed decisions based on algorithms. The latter is used in evidence-based management as the systematic, evidence-informed practice of management, incorporating scientific knowledge in the content and process of making decisions' ${ }^{12}$ and/or decision support systems ${ }^{13}$ that 'simulate cognitive decision-making functions of humans based on artificial intelligence methodologies (including expert systems, data mining, machine learning, connectionism, logistical reasoning) to perform decision support functions' ${ }^{14}$ The virtual assistants and financial algorithms, autonomous vehicles, robotics, blockchain smart contracts, automated online dispute resolution and other artificial intelligence (AI) technologies are already the part of our daily lives. Given the current presence of algorithms in industry, data processing, intellectual property, financial instruments, ${ }^{15}$ market, mail sorting, etc., further expansion is expected also in more decision-making software applications. ${ }^{16}$ On the other hand, predictive analytics has not set foot into legislation/regulation, ${ }^{17}$ although the latter effects a larger number of people. As said, the prediction has been in legislation so far stated

11 Ferrucci, D. et al. (2013) Watson: Beyond Jeopardy! Artificial Intelligence, 199-200.

12 Rousseau, D. M. (2013) The Oxford Handbook of Evidence-Based Management. Oxford: Oxford University Press, p. 3

13 Burstein, F., Brézillon, P. \& Zaslavsky, A. (2010) Supporting Real Time Decision-Making. New York, Dordrecht, Heidelberg, London: Springer Science \& Business Media.

14 Jao, C. (2012) Decision Support Systems. Olajnica: IntechOpen, p. 5.

15 Algorithmic trading is set out in Article 17 of Directive 2014/65/EU of the European Parliament and of the Council of 15 May 2014 on markets in financial instruments.

16 It is about the so-called "legal engineering" or applying the knowledge of IT professionals in the legal field, where science, statistics and software is used for legal services; it is a bridge between law, technology and the development of new (legal) products or services (e.g. smart data chain contracts) that understands data (facts and legal provisions) as programming and technical requirements in the direction of the more efficient, faster, more optimal achievement of legal objectives. A "legal engineer" is a person who, with the help of IT, co-creates legal processes.

17 Legislation and regulation are here used interchangeably. The automated individual decision-making, including profiling, is allowed under the conditions stated in Article 22 of GDPR (Regulation (EU) 2016/679 of the European Parliament and the Council of 27 April 2016 on the protection of natural persons with regard to the processing of personal data and on the free movement of such data, and repealing Directive 95/46/EC). 
in general forms (in words) that bring people together and ensure predictable behaviour. ${ }^{18}$

This paper claims that the pre-legislative practice of extracting information from data to determine patterns and predict future results and trends (written as general legal rules) could be more algorithm-based. At the start at least in a pre-preparation, draft or advising phase of legal acts. For adjudication many open questions are not addressed here, as the protection of human rights or due process deserves special attention. It is not only about data mining and profiling, ${ }^{19}$ but the whole range of AI as the field that 'studies the synthesis and analysis of computational agents that act intelligently', ${ }^{20}$ which could be used in the preparatory phase of legislation. Within the notoriously known increasingly complex and global world the inefficiency of planning ${ }^{21}$ in classic regulatory approaches is evident: law cannot predict future consequences, nor can they automatically accommodate to new circumstances without a legislator's 'by foot or manual' iterative amendment procedures. ${ }^{22}$ The old-fashioned way of drafting laws officially 'construct (formal) reality', but the latter is de facto also different not only due to the difference between the enactment and implementation time, but also due to amaller amount of data as needed.

Additionally, legislation can establish only how to act/decide when predetermined criteria are present (if-then), while planning contrary, means also thinking on things, their connections and exponential results. Planning thus proposes different, appropriate measures when things change (criteria and/or their weights change when things change). In the law, this could be at least partially achieved with legal scenarios: the legal conditional form of 'if-then' can be changed with 'what-if-then' approach where 'if' is based and determined on gathered data. This meaning of planning is absent

18 Boltanski, L. \& Thévenot, L. (2006) On Justification. Princeton and Oxford: Princeton University Press.

19 Profiling on a collective level could be focused on any form of automated processing of anonymised, grouped data evaluating collective aspects relating to persons, e.g. to analyse or predict aspects concerning the data collective's performance at some work, economic situation, health, collective preferences or interests, reliability or behaviour, location or movements.

20 Poole, D.L. \& Mackworth, A.K. (2010) Artificial Intelligence. Cambridge: Cambridge University Press, p. 3.

21 What legal act can tell us how e.g. the EU will react in the presence of new Covid-19 or another crisis?

22 The Covid-19 crisis is the clear example of this - this stands regardless of articles published in the most prestigious journals, e.g. Chang et al. (2021) Mobility network models of COVID-19 explain inequities and inform reopening. Nature, 589. 
in legislation; there is no room for proposed scenarios in changed conditions. At first, intent (and tools) are fixed in advance (e.g. this Act aims to minimise traffic accidents due to alcohol consumption), while at the second, endeavours are focused to achieve goals not only when conditions change, but also to accommodate new/different intentions/aims to new conditions (e.g. from the mentioned alcohol-based accidents to urgent road repairs); at legislation, a problem is known and a final result is left more or less to random future occurrences, while at planning the intention, tools and results are more ex ante and ex-post actively searched and selected. ${ }^{23}$ From the planning perspective, a static view on the rule of law can be in dynamic frames the very oppression of it (rules stay the same even when conditions change and are thus inefficient, or are made in the form of secondary legislation and transferred on the Executive branch, as was/is seen in the Covid-19 crisis). ${ }^{24}$ Could legal science hence develop its legislative Machina Speculatrix (Grey Walter's electromechanical tortoise that represents the beginnings of robotics), or what should be done to do so, to 'run an application, wait and see what will happen' (at least what will be proposed as a solution as it can be in medicine)? Already in 1977, Anthony D'Amato asked, 'Can/should computers replace judges?' 25 To calm down concerns, the legislator should still retain and maintain control, and it is also possible to suspend the execution of 'auto-rules' (a kill switch for the disengagement of the autopilot).

23 Planning tolls are more flexible: during planning, activities that may have a detrimental effect on a field of interest are reviewed in full, an extent of this impact is assessed, what measures and regimes are already in place are reviewed and a likelihood that targets will be achieved in a fixed time-cycle is assessed. On the basis of performed assessments, it is determined whether it is necessary to involve additional measures or stricter regimes for protection, while also financial consequences of measures for an individual fixed-year management period are determined. The mentioned shortcoming of inadaptability can be seen also in public reason and the rule of law that are both determined equally as legislation and mostly solely by state institutions.

24 Some estimate that 2 billion people have parliaments shut or limited by COVID-19. Provost, C., Archer, N., \& Namubiru, L. (2021) Alarm as 2 billion people have parliaments shut or limited by COVID-19. OpenDemocracy. Available from https://www.opendemocracy.net/en/5050/alarm-two-billion-people-have-parliamentssuspended-or-limited-covid-19 [Accessed 28 May 2021]. Based on more than 200 experts' responses it was determined that 'Covid-19 poses a special challenge for legislatures: the pandemic makes it difficult, daunting and even dangerous for parliaments to operate; all while creating a sense of emergency that empowers the executive branch and emboldens it to assert greater authority at the expenses of the legislature'. Bar-Siman-Tov, I. (2020) Covid-19 meets politics: the novel coronavirus as a novel challenge for legislatures. The Theory and Practice of Legislation, 8 (1-2), p. 33.

25 D'Amato, A. (1977) Can/Should Computers Replace Judges? Georgia Law Review, 11. 
If 'prediction is involved in every act of human behaviour that involves deliberate choice ${ }^{26}$ - how much of it is present in the legislation? This paper focuses on ways by which future possibilities can be built into the law, and how they can grow and be changed in different environments. The aim of this work is to extend our knowledge of prediction in legislation, especially to propose a way by which prediction can be better used in legislation.

This paper's idea is that this 'auto' moment of rules can be achieved by algorithms. Everything that is done online is now being watched and measured, which leads to better and better predictions. Based on data, different models are built that predict our actions. On another side of the screen, there is almost a person's avatar that can predict what he will do, and this applies also to the community as a whole. This condition can be improved with transparency (right to forget) and models of public interest, which could predict what is best for society as a whole. This is the work of advanced algorithms under the name of algorithmic regulation. While there are algorithms in the legal field that can help to individually fight crime, make judicial decisions on bail, sentencing and parole, ${ }^{27}$ prevent terrorism, score customers, decide on welfare benefits ${ }^{28}$ or flag for investigation hedge funds, there are none present in legislation/regulation. Although the notion of 'algorithmic regulation' was coined in 2013 by $\mathrm{O}^{\prime}$ Reilly, ${ }^{29}$ his focus was on the implementing phase of the regulation (whom to do), not on the constituting (drafting) one (what and how to do). A 2019 poll showed that 25\% of citizens from selected European countries are somewhat or totally in favour of letting AI make important decisions about the running of their country. ${ }^{30}$ The area of algorithms could attract increasing attention because of their ability to be used in general ${ }_{26}$ Carnap, R. (1966) Philosophical Foundation of Physics: An Introduction to the Philosophy of Science. New York: Basic Books, p. 18.

27 The Marshall Project, (2020) Algorithms. Available from: https://www.themarshallproject.org/records/3363-algorithms [Accessed 20 March 2021].Virginia's Sexually Violent Predator Act is the first law ever to specify the use of an actuarial prediction instrument. Under this Act the Virginia Department of Corrections is directed to review for possible commitment all prisoners who are about to be released and receive a score of four (such score translates into a prediction that the inmate, if released, would in the next ten years have a 55 percent chance of committing another sex offence) or more on the Rapid Risk Assessment for Sexual Offender Recidivism (a point system based on a regression analysis of male offenders in Canada).

28 Citron, D.K. (2008) Technological Due Process. Washington University Law Review, 85.

29 O'Reilly, T. (2013) Open Data and Algorithmic Regulation. In: Brett Goldstein (ed.) Beyond transparency: open data and the future of civic innovation. Sebastopol, CA: "O'Reilly Media, Inc.

30 Rubio, D. \& Lastra, C. (2019) European Tech Insights 2019. Available from: https://docs.ie.edu/cgc/European-Tech-Insights-2019.pdf [Accessed 13 March 2021]. 
legislation/regulation; public authorities possess large data and computer power needed for analysis can discover new patterns. Although algorithms can be used in individual procedures and collective ones, this paper is focused with the latter, on their nature of general predictions that apply to all. ${ }^{31}$ The key premise of this paper is that we need as complex and adaptive legislation as economic and other situations are; it should contain a corresponding variety, one able to give a response to diverse situations. There is a need for better planning in law that could exhibit sufficient variety in time of an Act's enactment and its implementation. This paper thus starts with the inefficiency of classic legal rules to address the uncertain future. The next section considers computational simulation of legal situations to be able address in the fourth section the collectivity of interests and unity of public interest, after which the conclusion follows in the fifth section.

\section{THE INEFFICIENCY OF CLASSIC LEGAL RULES IN THE UNCERTAIN, DYNAMIC FUTURE}

Jurisprudence as the calculation is known already from Leibniz and his geometrical analysis of rules: he 'insisted on applying the combinatorial method to calculate all possible legal cases and rules out of a set of simple elements. Leibniz recommends his method as a means for removing the uncertainty of legislation, and with it judicial discretion'. ${ }^{32}$ His call on 'Calculemus' (Let's calculate!) wanted to replace disputes by mechanical computing, because 'necessary truths, such as we find in pure mathematics and particularly in arithmetic and geometry, must have principles whose proof doesn't depend on the testimony of the senses' ${ }^{33}$ Leibniz refined ancient Egyptian knowledge on binary code that is still the current language of computers, but along his saying that nature never makes leaps (or nothing takes place suddenly) ${ }^{34}$ aka the Law of Continuity also applies to algorithms - they can jump, but we have to be prepared for such jumps.

31 In the case of transferring words into the programming language (program code), management of an individual administrative procedure e.g. for granting social assistance may - due to transmission errors - become in fact a general rule that will apply to all further cases (when the program "does not allow" a different decision). All algorithms applied in individual cases are predetermined in general legislation so it matters more how algorithms here are defined and allowed.

32 Artosi, A., Pieri, B. \& Sartor, G. (2013) Leibniz: Logico-Philosophical Puzzles in the Law: Philosophical Questions and Perplexing Cases in the Law. Dordrecht: Springer Science \& Business Media, p. xxv.

33 Leibniz, G.W.F.V. (1996) Leibniz: New Essays on Human Understanding. Cambridge: Cambridge University Press, p. 3. 
Planning in the law has so far meant production of various concepts (intuitively) raised in mental frames, which were then in time (dis)confirmed by practice (trial and error), not by calculation. When concepts show a relevant level of unity, lawyers are accustomed to see rationality (substantial grounds) in the law, regardless of bad results. Legal science still mainly uses the dichotomous (if-then), Boolean yes-or-no truth values rather than more-or-less type of legal rules (as it is present in the principle of proportionality). The first are based on traditional dual logic, where a statement is true or false and nothing in between, while e.g. in fuzzy set theory ${ }^{35}$ (and even more in quantum theory), an element is based on potentiality and can either belong to a set or not. This can be hard to imagine in legal frames; on the other hand, fuzziness and/or uncertainty, imprecision and vagueness are also present in human language, as well as in the human judgment, evaluation and (legal) decisions (a person takes a more certain decision, i.e. more probable). Legal science still formally uses general legal rules based on determinism rather than on potentiality, predictability or anticipation, although the last three are de facto present in the indeterminate legal notions (e.g. public interest, security, health). Similarly, this indeterminism is present also in adjectives: e.g. a nice person or a tall building. This applies also for the standards of evidence (e.g. preponderance of evidence, sufficient evidence) with their degrees of truth rather than true or false statements (although the result is usually taken as such: something is allowed/prohibited, acquittal/conviction). Even the elements of the well-known legal principle of proportionality (the legitimate aim, suitability, necessity and proportionality sensu stricto) are determined by degrees and linguistic rules, and not by (numeric) variables (although this could be done e.g. with Bayes theorem).

It is hence a smaller problem not to know something counterintuitive than to know but still do nothing. Reality is rarely deterministic, precise

34 Leibniz, G.W.F.V. (1996) Leibniz: New Essays on Human Understanding. Cambridge: Cambridge University Press.

35 Zadeh, the founder of the theory of fuzzy (uncertain) logic (that resembles human reasoning that "computes" words not numbers), described the principle of incompatibility between precision and complexity: 'as the complexity of a system increases, our ability to make precise and yet significant statements about its behavior diminishes until a threshold is reached beyond which precision and significance (or relevance) become almost mutually exclusive characteristics'. Zadeh, L.A. (1973) Outline of a new approach to the analysis of complex systems and decision processes. IEEE Transactions on systems, Man, and Cybernetics, 3 (1). The perspective of fuzzy logic can help to describe what is (not) going on also in legal science (that also does not operate with numbers, but with words), although the principle of legal certainty indicates an assumption that rules' parameters are known and there are no doubts about their values or their occurrence. 
in character, or certain. It is mainly complex, assembled from numerous parts and their relations. It is hardly ever directly consequential and more often than not exponential due to the nonlinearity of complex systems (society, people, language, etc.): they often operate not accordingly with our intuition, insight, or comprehension, but are based on relations. As the law is also a complex system it should be also addressed with such tools; this holds all the more when the future is considered in the form of general legal rules. That properties of some system cannot be reconstructed from the knowledge of corresponding parts can be counterintuitive, but a system cannot be fully comprehended even when its relevant legal, financial, economic, political, psychological, ecological and other relevant subsystems are known. ${ }^{36}$ Along with knowable parts, there are relations and flows among and through them vis-à-vis stocks, outer boundaries, thresholds, sensors, measuring instruments, patterns, feedback and other elements present, known from systems theory. They all 'mess up' the legislator's clear, deterministic and reductionistic painting. Systems can be known from a point of our interest because a system is not a thing, but a list of (chosen) variables $^{37}$ - when a deterministic variable is changed to the dynamic one, there is a different system present. Remember that trends are nothing but symptoms of the underlying system structure, ${ }^{38}$ and when this structure is static, also results are such (and hence more or less left to chance). For some, also the human mind non-stop calculates; as regards numerical processing, Dennet explains that 'human consciousness... [is] in terms of the operations of a virtual machine, a sort of evolved (and evolving) computer program that shapes the activities of the brain', 39 while to Pinker '[t]he mind is a system of organs of computation, designed by natural selection... The mind is what the brain does; specifically, the brain processes information and thinking is a kind of computation'. ${ }^{40}$ Discovered regularities through (mental) computation are later transferred into decisions or 'patterns of a higher order' ${ }^{41}$ One of the main lessons of AI is that 'successful agents [something that acts in an environment] exploit

\footnotetext{
36 Klir, G.J. \& Elias, D. (2003) Architecture of Systems Problem Solving. New York: Springer Science \& Business Media.

37 Ashby, W.R. (1957) An Introduction to Cybernetics. London: Chapman and Hall.

38 Meadows, D.H. (2008) Thinking in Systems: A Primer. London: Chelsea Green Publishing.

39 Dennet, D.C. (2012) Pojasnjena zavest. Ljubljana: Krtina, p. 509.

40 Pinker, S. (1997) How the Mind Works. London: Penguin Books, p. 21.

41 Beer, S. (1966) Decision and Control: The Meaning of Operational Research and Management Cybernetics. Chichester: John Wiley \& Sons, p. 7.
} 
the structure of the world ${ }^{42}$ mainly through probability distributions over various effects that determine which characteristic best predicts the value of another one (reasoning under uncertainty).

The calculation can be seen also in the law, although not on the open floor. At the enactment of the law, limits are set for an allowed behaviour which a person can exhibit in any predetermined situation; in the next step the same person can behave differently, and his move is not completely determined although it can be (roughly or more mathematically) predicted (probability of all moves can be known through the base rate). Such behaviour introduces randomness in the law, which is enhanced in the random (non-deterministic) environment, where an observed pattern of probabilities can be seen over a while through past examples. Legislation many times resembles more to bootstrapping (based on a self-starting process supposes to advance without external input) than to real tools of human development: decision-makers enact a system in the form of general legal rules (of constitutional, legislative nature) that address (or try to manage) an unknowable future from the point of (more or less) knowable present time (they 'blindfolded throw spears/hypotheses in an intended direction') and 'pretend' they effectively and efficiently addressed the future's vagueness; the latter always co-determines a final rule's content given circumstances.

A democratic (especially majoritarian) way per se is hence not enough to obtain the most relevant solution (as only number or the majority is not synonymous with the best option). It hence matters how one betters oneself by one's efforts, what approaches legislators could use in general legislation - when knowing the future is uncertain and thus unknowable. Incompatibility between the legislation and its (static, ex ante) legal principle of certainty rises with the growing complexity; parliaments in such conditions transfer regulatory powers on the Executive (to be able to quickly respond to change conditions with secondary legislation) on the account of democratic legitimacy. This will hold until some other ways are not discovered by which at least a result's procedural certainty (how a result is formed although without knowing when and where) will remain at the legislative branch of power. The inefficiency of classic (static, unadaptable, inflexible) legal rules to address the uncertain future is not

$\overline{42}$ Poole, D.L. \& Mackworth, A.K. (2010) Artificial Intelligence. Cambridge: Cambridge University Press, p. 492. 
some abstract idea, but the inevitable fact regardless of how much the principle of legal certainty is appreciated (although even ancient Greeks used sortition, i.e. lottery, selection by lot or allotment for the selection of political officials). In the dynamic change-prone environment, the mentioned principle is not so certain anymore. Decisions under uncertainty, i.e. in the complex environment, are always false up to a point, so they should be on the other hand easier to control, they should be highly corrigible and flexible with the built-in future alternatives, sensitive to errors or deviations. Preparedness to change when conditions change ${ }^{43}$ is the basic difference between the static and flexible rules, and legislation should be no exception here.

\section{TOWARDS COMPUTATIONAL SIMULATION OF LEGAL SITUATIONS}

In this section, some predispositions (stated in italicised text) are given based on which future legal situations will be probably more calculated than legislated/decided. Supercomputers are already used for weather forecasting, spacecraft aerodynamics and other areas, where they can produce meaningful conclusions out of apparently random data. They could be used also in the law that effects the lives of all inhabitants in all countries.

Of course, software is not a magic formula. In the 21st century, IT can make an even larger distance between decision-makers and citizens as classic legislation. On the other hand, concerns over software systems may be many times 'proxies for concerns about power and inequality in general, not software specifically': ${ }^{44}$ the fear of the unknown (e.g. a deep state or an unknown influencer with control) may be the larger problem than software (there are almost 5 billion internet users). In practice, the final results are many times different from predicted ones, and the distance, technology and intricate webs of connections between institutions, their employees, and citizens always cause a lack of accountability. The reason for such deficiency is that one contributes only tiny bits to a final result that is additionally self-made from the connections themselves (remember

\footnotetext{
43 The saying attributed to the economist John Maynard Keynes is: "When the facts change, I change my mind. What do you do, Sir"?

44 Desai, D.D. \& Kroll, J.A. (2017) Harvard Journal of Law \& Technology, 31, p. 5.
} 
Arendt's rule by nobody ${ }^{45}$ ). In complex matters there is always a high probability that future occasions or frames will change or deviate from the outlined formal paths in due time; this exhibits classic regulations applied in the dynamic environment, and at algorithms it is the same: also here the other, with accountability tightly connected classical legal principle of transparency cannot be helpful because seeing a system's internal parts (a revealed source code) cannot provide full understanding of their (later) interconnections and consequences (this can confirm updates of new software releases, where bugs or bad inputs are not seen directly from the source code, but from erroneous functions). ${ }^{46}$ In this manner, the old Turing test can still be helpful. ${ }^{47}$ It seems people 'rather see' bad things to happen when they are caused by human factor than by a 'machine' (a presumption is the first may be more controllable). Connections (in the form of unwanted side-effects), not some premeditated intentionally evil human designer, are in the majority of cases, a cause of discrimination and other rights' violations. The first step towards a larger use of software in law is understanding, knowing of modus operandi of systems, of everything connected, of understandable, although not fully predictable.

45 The rule by Nobody is perhaps the most formidable form of a dominion of man over man: 'bureaucracy or the rule of an intricate system of bureaus in which no men, neither one nor the best, neither the few nor the many, can be held responsible, could be properly called the rule by Nobody. If in accord with traditional political thought, we identify tyranny as a government that is not held to give an account of itself, rule by Nobody is the most tyrannical of all, since there is no one left who could even be asked to answer for what is being done. It is this state of affairs, making it impossible to localise responsibility and to identify the enemy, that is among the most potent causes of the current world-wide rebellious unrest, its chaotic nature, and its dangerous tendency to get out of control and to run amok. Bureaucracy is the form of government in which everybody is deprived of political freedom, of the power to act; for the rule by Nobody is not no-rule, and where all are equally powerless, we have a tyranny without a tyrant'. Arendt, H. (1972) Crises of the Republic: Lying in Politics, Civil Disobedience on Violence, Thoughts on Politics, and Revolution. New York: Harcourt Brace Jovanovich, p. 138.

46 Accountability in systems that span multiple administrative domains is envisaged as 'an accountable system that maintains a tamper evident record that provides non-repudiable evidence of all nodes' actions. Haeberlen, A., Juznetsov, P. \& Druschel, P. (2007) PeerReview: Practical Accountability for Distributed Systems. ACM SIGOPS Operating Systems Review, 41 (6). Desai and Kroll speak about computer science accountability: 'such evidence would provide records of what actions were taken and why, with a focus on how that evidence will be used to hold the system's creators or operators accountable for those actions'. Desai, D.D. \& Kroll, J.A. (2017) Trust But Verify: A Guide to Algorithms and the Law. Harvard Journal of Law \& Technology, 31. Algorithms should be hence technically accountable and analysable.

47 Designed by Alan Turing as an imitation game in which an evaluator must decide whether he is speaking with a machine or with a human, while both are hidden behind a curtain. In this sense, one could conclude that a decision-making algorithm is as good as a human decision-maker when an assessor would not be able to determine from a given decision and its argumentation who made it. Turing, A.M. (1950) Computing Machinery and Intelligence. Mind, 59 (236). 
Laws already at their enactment exhibit the probability for which formulas are better than intuition or common sense. Legal goals are stated, while their methods of reaching them are put down in general and hence quite unpredictable in detail. Due to equality demand, such technique is appropriate, but for the more static conditions; for the more dynamic ones some methods can better achieve probability (a lot as one example of chance in elections, algorithms, trial and error or other effective procedures to calculate/show a result) with the help because of probability, of the possibility of better/quicker adaptation. To be adapted one should control its essential variables vis-à-vis the environment, so the latter then act on the former appropriately, and in the environment with more and more data, human computing power is not enough. Here is the place for algorithms that could run a procedure to resolve common biases of discrete prediction: for Nobel laureate they are the neglect of base rates and insensitivity to the quality of information, so 'to maximise predictive accuracy, final decisions should be left to formulas, especially in low validity [complex] environments'. ${ }^{48}$ Algorithms are no magic stick (they 'can be compared on the time taken, the space used and the quality or accuracy of the results' ${ }^{49}$ ) but they have calculative power: people do not think by the lengthy logical equations; they use the classic laws of logic, accustomed to their daily lives. Traditionally, acceptable modes of behaviour have so far provided sufficient solutions for life, although we are many times not aware of cognitive shortcomings and/or intuitive fallacies. People have a natural inclination to deliberation, cooperation, the recollection of knowledge (ideas, experiences, heuristics, logical reasoning), and pragmatic reasoning, but for inferential purposes ' $[\mathrm{t}] \mathrm{he}$ human brain is relatively inefficient for noticing, selecting, categorizing, recording, retaining, retrieving, and manipulating information'. ${ }^{50}$ There are two modes of data combination for a predictive purpose: the clinical (expert) method relies on human judgment, based on informal contemplation and sometimes discussion with others, and the mechanical method that involves a formal, algorithmic, ${ }^{51}$ objective procedure (e.g. equation) to reach the decision. Meehl found that empirical comparisons

\footnotetext{
48 Kahneman, D. (2013) Thinking, Fast and Slow. Farrar, Straus and Giroux, New York, p. 225.

49 Poole, D.L. \& Mackworth, A.K. (2010) Artificial Intelligence. Cambridge: Cambridge University Press, p. 83.

50 Grove, W.M. \& Meehl, P.E. (1996) Comparative Efficiency of Informal (Subjective, Impressionistic) and Formal (Mechanical, Algorithmic) Prediction Procedures: The Clinical-Statistical Controversy. Psychology, Public Policy, and Law, 2, p. 316.
} 
of the accuracy of the two methods (136 studies over a wide range of predictands) show that the mechanical method ${ }^{52}$ is almost invariably equal to or superior to the clinical method. Meehl already in 1955 found overwhelming evidence for a disturbing conclusion: upon the reviewed results of 20 analysed studies, he concluded that predictions based on simple statistical scoring were generally more accurate than predictions based on expert judgment. ${ }^{53}$ The statistical algorithm was more accurate than experts. Meehl's book shocked clinical psychologists, but 'the score in the contest [of roughly two hundred studies] between algorithms and humans has not changed. About $60 \%$ of the studies have shown significantly better accuracy for the algorithms' ${ }^{54}$

Behaviour is latent in the interaction of parts ${ }^{55}$ influenced by the structure. ${ }^{56}$ Actions and results are hence not caused primarily by the external environment, but by interrelationships ${ }^{57}$ that cause new things. This is known as emergence and/or 'the appearance of a level of complexity more advanced than the existing components of a system' ${ }^{58}$ The Nobel Prize-winning chemist Ilya Prigogine established all sufficiently

51 Algorithms are a simple set/series of rules for solving problems in a finite number of steps. They are 'methods for solving problems that are suited for computer implementation'. Sedgewick, R., \& Wayne, K. (2011). Algorithms. Upper Saddle River, NJ: Addison-Wesley Professional, p. 3. Algorithms are e.g. simple recursive, backtracking, divide and conquer, dynamic programming, greedy, branch and bound, brute force, and randomised algorithms. They perform calculation, data processing, or automated reasoning tasks. Christian, B. \& Griffiths, T. (2016) Algorithms to Live By: The Computer Science of Human Decisions. New York: Henry Holt and Co. On the other hand, there are warnings against the "logic of secrecy" obtained from a vast amount of data. Pasquale, F. (2015) The Black Box Society: The Secret Algorithms That Control Money and Information. Cambridge: Harvard University Press. But still, such results can be confirmed by an appropriate institution before they are applied in real cases.

52 Mechanical prediction includes the output of optimized prediction formulas, such as multiple regression or discriminant analysis; unoptimized statistical formulas, such as unit-weighted sums of predictors; actuarial tables; and computer programs and other mechanical schemes that yield precisely reproducible (but not necessarily statistically or actuarially optimal) predictions. Grove, W.M. \& Meehl, P.E. (1996) Comparative Efficiency of Informal (Subjective, Impressionistic) and Formal (Mechanical, Algorithmic) Prediction Procedures: The Clinical-Statistical Controversy. Psychology, Public Policy, and Law, 2, p. 296.

53 Meehl, P.E. (2013) Clinical Versus Statistical Prediction: A Theoretical Analysis and a Review of the Evidence. Northvale, N.J.: Echo Point Books \& Media.

54 Kahneman, D. (2013) Thinking, Fast and Slow. New York: Farrar, Straus and Giroux, p. 223.

55 Bertalanffy, L.V. (1968) General system theory: foundations, development, applications. New York: George Braziller.

56 Senge, P.M. (2010) The Fifth Discipline: The Art \& Practice of The Learning Organization. New York: Crown Publishing Group.

57 Ackoff, R.L. (1978) The Art of Problem Solving: Accompanied by Ackoff's Fables. New York: John Wiley \& Sons.

58 Feltz, B., Crommelinck, M. \& Goujon, P. (2006) Self-organization and Emergence in Life Sciences. London: Springer Science \& Business Media, p. 341. 
complex systems can develop unpredictable emergent behaviour ('the interaction of a system with the outside world, its embedding in nonequilibrium conditions, may become in this way the starting point for the formation of new dynamic states of matter - dissipative structures ${ }^{59}$ ) far from equilibrium (very small perturbations or fluctuations can become amplified into gigantic, structure-breaking waves). In such conditions, dissipative structures and/or a system may reorganise itself (selfreorganisation) in new order through fluctuations. ${ }^{60}$ The traditional regulatory thinking neglects this basic system's predisposition of interconnections - it looks only towards final goals (regardless of how they are assembled) and assumes a single (of few) cause(s) rather than the multiple interrelated causations ${ }^{61}$ or at least correlations that have to be checked. 'When the organism has to adapt (to get its essential variables within physiological limits) by working through an environment that is of the nature of a Black Box, then the process of trial and error is necessary, for only such a process can elicit the required information'. ${ }^{62}$ Having this in mind, Ashby built an adapter and/or the Homeostat, a device built to know its exact nature and to observe what will happen in various conditions. In all equality-at-the-start cases stability is then upset by the environmental randomness, so to cope with it, a variety should be put in by the installed 'pointers' (step-functions) as intermediate targets that show a path towards main goals. Ashby named this ultrastability when second-order feedbacks ${ }^{63}$ veto all states of the equilibrium except those that leave each essential variable within its proper limits.

Interactions change the Act's intentions, tools and goals. Interactions among parts when the system runs (when a legal Act is a valid vis-à-vis to other valid acts and the environment) can change daily; a factual state

59 Prigogine, I. \& Stengers, I. (1984) Order Out of Chaos. New York: Bantam Books.

60 Nicolis, G. \& Prigogine, I. (1977) Self-organization in nonequilibrium systems: from dissipative structures to order through fluctuations. London: Wiley.

61 The traps of non-systems thinking lie in two simple dimensions; firstly, avoiding the inevitable interconnectivity between variables - the trap of reductionism, and secondly, working on the basis of a single unquestioning perspective - the trap of dogmatism. Reynolds, M. \& Holwell, S. (2010) Systems Approaches to Managing Change: A Practical Guide: A Practical Guide. London: Springer Science \& Business Media.

62 Ashby, W.R. (1960) Design for a Brain: The Origin of Adaptive Behavior. London: Chapman and Hall, p. 83.

63 The organism that can adapt has a motor output to the environment and two feedback loops. The first gives the organism non-affective information about the world around it, and the second carries information about whether the essential variables are (not) driven outside normal limits and it acts on (external) parameters. The first feedback plays its part within each reaction; the second determines which reaction shall occur. Ashby, W.R. (1960) Design for a Brain: The Origin of Adaptive Behavior. London: Chapman and Hall, p. 82. 
of affairs hence becomes different from the one envisaged in a preparatory phase. A solution for this can be stochastic indicators and their relevant sensors: such indicators cannot only spot changes but also impartially determine relevant connections (e.g. randomised algorithms compare nearby neighbours and switch to one with the highest efficiency, known as stochastic local search), because 'groups whose members represent disparate points of view or special interest populations may err by focusing on their shared perspectives and thereby negating any advantage that accrues from multiple sources of diverse input'.64 To Simon ${ }^{65}$ in the 'information-rich' world of information oversupply, now attention, not information is the scarce good. Actions are based not on data, but on our attention (here through indicators and sensors) which collects the first. What emerges from legal Acts is conditioned on the regulator's attention, while in the non-linear, complex matters, all the more when algorithms are used, the regulator can only define a system's (i.e. Act's) boundaries. There are many things that can go wrong in complex matters, so also the classic, very exact system of tort and liability cannot be used without adaptations. Interactions cause emergent new things that at the same time interact with similar, but higher and other systems. Liability in complex matters will be difficult to impose on those who would be considered liable under traditional liability, as they will rarely have a reasonable opportunity to control or anticipate potential risks. The theory of adequate causality (among several circumstances related to the occurrence of damage, the cause is considered to be the one that, according to usual life experience, within the regular course of things, leads to the same consequence) that is commonly used in determining liability, fails here because causation (normality) cannot be firmly established, while objective, strict liability (used for the previously known ultra-hazardous activities) is likely to be too harsh for algorithm developers (because the hazard is not foreseeable, and they also do not know whether there is a risk of large-scale damage, even if all actors acted carefully). Two approaches can be proposed to provide compensation for victims of injuries 'caused' by learning ${ }^{66}$ algorithms, similar to the sophisticated robotic vehicles: the first is to 'adopt a no-fault insurance scheme... The second... is

64 Stasser, G. \& Titus, W. (1985) Pooling of unshared information in group decision making: Biased information sampling during discussion. Journal of Personality and Social Psychology, 48 , p. 1477.

65 Simon, H.A. (1996) The Sciences of the Artificial. Cambridge: The MIT Press. 
to use a no-fault insurance type scheme that is funded by imposing the costs of injuries on distributors, who would then be immune from tort liability' ${ }^{67}$ Liability in fields where learning algorithms will be used, will probably go from the 'Laplace's demon' (that 'knows' a complete physical state of the present universe) towards non-linear quantum mechanics, where outcomes cannot be predicted, but solely their probability can be calculated (with this they resemble to lot or random voting used in Ancient Greece).

Changes recorded in algorithms can be systematically ex ante (a prior analysis) and ex post ${ }^{68}$ (a posterior analysis) analysed with the help of indicators. This could be done based on event data records, founded not only vis-à-vis the input-output relation - and external factors such as the whistle-blower's, public interests and private actions ${ }^{69}$ - but also on several stochastic indicators, as the mentioned relation cannot incorporate all relevant factors as inputs. Indicators enable openness and transparency and at the same time prevent the above mentioned the rule of Nobody. Predictive systems are built on correlations and algorithms that change dynamically; for Citron procedural regularity is hence essential to prevent 'arbitrariness by the algorithm' ${ }^{70}$ The time is irreversible, and to manage it there must be real-time sensors by which a controller could gain insight into the current state of affairs (of [anti]discrimination etc.) in the shortest time possible. Indicators of this could be stochastically taken from a larger list to prevent subjectivity in focusing only on some of them. This is what complex algorithms do: they process decisions from stochastic inferences based on determined correlations. On the other hand, the more power of decision-making algorithm has, the more its stochastically operating classifications could risk discrimination; it should be thus 'programmed to the conditions under which it can exploit its advantages

${ }_{66}$ Learning typically means finding the best model that fits the data... There are many issues beyond fitting data, including how to incorporate background knowledge, what data to collect, how to represent the data and the resulting representations, what learning biases are appropriate, and how the learned knowledge can be used to affect how the agent acts. Poole, D.L. \& Mackworth, A.K. (2010) Artificial Intelligence. Cambridge: Cambridge University Press, p. 26.

67 Hubbard, F.P. (2016) Allocating the risk of physical injury from "sophisticated robots": Efficiency, fairness, and innovation. In: RyanCalo, Michael A. Froomkin, Ian Kerr (eds), Robot Law. Cheltenham, Northampton: Edward Elgar Publishing, p. 45.

68 As in the known ex ante and ex post regulatory impact assessment with the difference that automatically processed data can be provided earlier than otherwise.

69 Desai, D.D. \& Kroll, J.A. (2017) Harvard Journal of Law \& Technology, 31.

70 Citron, D.K. (2016) Big Data Should Be Regulated by 'Technological Due Process'. Available from: https://www.nytimes.com/roomfordebate/2014/08/06/is-big-data-spreadinginequality/big-data-should-be-regulated-by-technological-due-process [Accessed 18 June 2020]. 
and avoid unethical decisions'. ${ }^{71}$ Jones and Baumgartner propose a stochastic, not attention-driven updating of policies:

"in politics, a good starting point is to ask how policymakers attend to and prioritize information. The trick is in the combining... Combining messages means both getting the sources right and getting the weights right... If a few indicators [instead of a single one] are simultaneously monitored, the result is a normal distribution of information. The best way [to prioritise information from many sources] would be to weight the information streams by importance and add them to make an index... If decision-makers act on the "news," rather than a basket of indicators, they will produce a distribution of outcomes that is not normal. Attention-driven choice guarantees nonnormal distributions of policy outputs."72

Learning algorithms embedded in adaptive legislation. Algorithms that learn themselves by running trial and error experiments or make other real, mathematical or virtual attempts to find a solution, are learning (autonomous) algorithms. ${ }^{73}$ One of them is machine learning (ML) as the method which processes data to extract patterns appropriate for application in new situations. The goal is to adopt a system to a specific input-output transformation task. ${ }^{74} \mathrm{ML}$ introduces 'code-based rules which are inherently dynamic and adaptive - thus replicating some of the characteristics of traditional legal rules characterized by the flexibility and ambiguity of natural language' ${ }^{75}$ A legal act (statute) is fully stable only when enacted. After this, it can become ultra-stable only when it controls its internal essential variables that have to be within their normal limits (homeostasis) vis-à-vis the external environment (by blocking the flow

71 Martini, M. (2020) Regulating Algorithms: How to Demystify the Alchemy of Code? In: Martin Ebers, Susana Navas (eds) Algorithms and Law. Cambridge: Cambridge University Press, p. 107.

72 Jones, B.D. \& Baumgartner, F.R. (2005) A Model of Choice for Public Policy. Journal of Public Administration Research and Theory, 15, pp. 330, 336.

73 An effective model of a learning process... begins operations with an arbitrary target of preferred states fixed by the limited human intelligence, and uses its uneconomical random mutations to produce slow other patients by Marcovian evolution. Gradually the arbitrariness is replaced by purposive selection, the lack of economy by directed mutation and the slowness of adaptation by rapid learning. Beer, S. (1959) Cybernetics and Management. London: The English University Press LTD, p. 149.

74 Lahmiri, S. (2016) Prediction of International Stock Markets Based on Hybrid Intelligent Systems. In: Mehdi Khosrow-Pour (ed.) Handbook of Research on Innovations in Information Retrieval, Analysis, and Management. Hershey: IGI Global, pp. 110-124.

75 Hassan, S. \& De Filipi, P. (2017) The Expansion of Algorithmic Governance: From Code is Law to Law is Code. Field Actions Science Reports, 17, p. 90. 
of information to essential variables and by amplifying/switching to sources towards a desired goal). ${ }^{76}$ An algorithm receives a data set from which it infers information about data properties. That 'information allows the algorithm to make predictions on other data. This is possible because almost all non-random data contains patterns, and these patterns allow the machine to generalize. ${ }^{77}$ ML algorithms constantly refine their rules based on the received and collected data to better match their context of the application, and hence learn. When the ML algorithm uses multiple layers in the network, it is named deep learning (e.g. deep neural networks, deep belief networks, recurrent and convolutional neural networks) that advances on the extensive knowledge of correlations and patterns (which are invisible or even irrelevant to human decision-makers) that enable better decisions than an individual human could do. This 'might become difficult for people to not only understand but also question the legitimacy of the rules that are affecting their lives' ${ }^{78}$ On the other hand, people have numerously questioned the legitimacy of rules that led to serious consequences. Computer-based simulations have a key role in mathematical models, scientific investigations, and design to analyse problems that would be too expensive, dangerous, or even impossible to study by direct experimentation. ${ }^{79}$ The concept of a data warehouse is also helpful here due to the possession of a large amount of external and internal information by organisations; their challenge is how to determine data quality and use it for management and/or decision-making that would not discriminate against people. Such data could be used for real-time information seen on interactive dashboards, reporting, predictive analytics, and as inputs for managerial decision-making. Algorithmic regulation embodies a version of the machine and deep learning as a product of the neural nets, genetic algorithms ${ }^{80}$ and/or other arrangements of feedback loops that can accommodate means to new situations; as they also generate actions unpredictable ${ }^{81}$ to human decision-makers, an Act's core intent should be given or accommodated by the legislator.

76 Ashby, W.R. (1960) Design for a Brain: The Origin of Adaptive Behavior. London: Chapman and Hall.

77 Segaran, T. (2007) Programming Collective Intelligence: Building Smart Web 2.0 Applications. Beijing; Sebastapol CA: O'Reilly Media, p. 3.

78 Hassan, S. \& De Filipi, P. (2017) The Expansion of Algorithmic Governance: From Code is Law to Law is Code. Field Actions Science Reports, 17, p. 90.

79 Miranda, F. \& Abreu, C. (2016) Handbook of research on computational simulation and modeling in engineering. Hershey: Engineering Science Reference. 
Adaptive legislation as a form of artificial intelligence. AI can be divided into the 'rule-based' approach and the 'neural networks' approach. In the former (also called 'symbolic systems' or 'expert systems'), attempts are to 'teach' computers to think by encoding a series of logical rules: ifthen. This approach is good for simple and well-defined tasks, but falls short when the number of possible choices expands. The latter approach instead of trying to teach the computer rules mimics the human brain itself: rules are not given to make a decision, but lots of examples of a relevant phenomenon are fed into the neural networks, where the networks themselves identify patterns within the data. ${ }^{82}$ Numerous machine learning algorithms linked to mathematics and statistics (correlation analysis in regression are the basic model of machine learning). The business world uses decision support systems (DSS) as data systems that support decisionmaking. DSS is 'a computerized system that provides executives with easy access to internal and external information that is relevant to their critical success factors' ${ }^{83}$ DSSs based on data banks, analytic and statistical functions interactively help to make decisions on the fast-changing, complex and interrelated problems that are present sometimes below 'the human radar'; they provide immediate decision modelling, and thus allow future planning. DSS also use algorithms based on neural networks and genetic algorithm, ${ }^{84}$ use data mining algorithms and are used for multicriteria satisfaction analysis (MUSA) method for measuring job satisfaction, ${ }^{85}$ etc.

80 Genetic algorithms select pairs of individuals and then create new offspring by taking some of the values for the offspring's variables from one of the parents and the rest from the other parent, loosely analogous to how DNA is spliced in sexual reproduction genetic algorithms select pairs of individuals and then create new offspring by taking some of the values for the offspring's variables from one of the parents and the rest from the other parent, loosely analogous to how DNA is spliced in sexual reproduction. Poole, D.L. \& Mackworth, A.K. (2010) Artificial Intelligence. Cambridge: Cambridge University Press, p. 142.

81 The algorithm's innate unpredictability comes - along the algorithm's equations and connections - from its inputs as sets of information from the Internet or other special bases (aka data-mining engines, e.g. Google, Amazon). That set of data non-stop changes due to users' actions, who all the time contribute new bits of information. When different algorithms react on such enormous collection of non-stop changing inputs, the unpredictability of outputs became its output (unpredictability by default).

82 Lee, K.-F. (2018) AI Superpowers: China, Silicon Valley, and the New World Order. Boston and New York: Houghton Mifflin Harcourt.

83 Watson, H.J., Rainer, R.K. \& Koh, C.E. (1991) Executive Information Systems: A Framework for Development and a Survey of Current Practices. MIS Quarterly, 15 (1), p. 14.

84 Bukharov, O.E. \& Bogolyubov, D.P. (2015) Development of a decision support system based on neural networks and a genetic algorithm. Expert Systems with Applications, 42.

85 Aouadni, I. \& Rebai, A. (2017) Decision support system based on genetic algorithm and multi-criteria satisfaction analysis (MUSA) method for measuring job satisfaction. Annals of Operations Research, 256. 
Algorithms will have a role in the law, sooner or later. The U.S. Food \& Drug Administration has so far approved more than 34 smart algorithms in healthcare; ${ }^{86}$ if algorithms can save lives, they can also help to regulate them, but before their real application, their modus operandi should be explained to avoid the fears of giving up regulation to something that cannot be understood either controlled. There is no surprise that some people already consider algorithms ${ }^{87}$ as artificial persons: 'in Law, companies have the rights and obligations of a person. Algorithms are rapidly emerging as artificial persons. Intelligent algorithms will require formal training, testing, verification, certification, regulation, insurance, and status in law' ${ }^{88}$ About planning horizon (i.e. how far algorithms can 'look into the future'), there is likely to be a wide-ranging debate on the appropriateness of individual algorithms vis-à-vis the rate of change in the environment: from those that are similar to weather forecasts to those that can through forecasting address longer periods, a probability of occurrence and the potential consequences of their or somebody else's actions.

\section{COLLECTIVITY OF INTERESTS VS. UNITY OF PUBLIC INTEREST}

Sometimes there is no data, and new arrangements can be time-consuming or expensive. When data is not available use collective intelligence. Working in and with the more various, independent groups could also be the other way to obtain data. Computational simulation and modelling/algorithms can group the power of computers with such naturalistic human conditions. In such cases, decision-makers could use public opinion (public could be

86 TMF (2019) FDA Approvals for Smart Algorithms in Medicine in One Giant Infographic The Medical Futurist. Available from: https://medicalfuturist.com/fda-approvals-foralgorithms-in-medicine [Accessed 21 September 2020].

87 The key algorithm technologies are Artificial Intelligence (AI; AI and machine learning systems able to perform tasks normally requiring human intelligence), Blockchain Technologies (technology underpinning digital currencies and transactions, that secures, validates and processes transactional data), Internet of Things (IoT; - is the inter-networking of 'smart' physical devices, vehicles, buildings, etc. that enable these objects to collect and exchange data) and Behavioural and Predictive Analytics (the analysis of large and varied data sets to uncover hidden patterns, unknown correlations, customer preferences etc. to help make informed decisions). These four technologies are intimately linked: AI provides the algorithms, blockchain the data storage and processing infrastructure, IoT the data devices, and behavioural/predictive analytics are important for (human) behaviour analysis. Barnett, J., Soares, A.K. \& Treleaven, P. (2017) Algorithms and the Law. Available from: http://www.jeremybarnett.co.uk/algorithms-and-the-law [Accessed 21 October 2020].

88 Barnett, J., Soares, A.K. \& Treleaven, P. (2017) Algorithms and the Law. Available from: http://www.jeremybarnett.co.uk/algorithms-and-the-law [Accessed 21 October 2020]. 
used also for testing a computer program's and/or algorithm's efficiency) that should not be in the time of information era so hard to get and analysed from the point of collective. Individuality can be spotted only in its initial condition (and also hereby disregarding all previous connections that brought this individuality on a start line). 'We cannot claim that we know the (collective) order of dynamics from particular evidence; "order" is the universal collective property. We have to study a group of motions with various initial conditions and pry the universal properties out of the bundle of orbits'. ${ }^{89}$ Collecting data from answers (from a large group of various, independent people) enable statistical conclusions about the group that no individual member cannot know: 'building new conclusions from independent contributors is really what collective intelligence is all about'. ${ }^{90}$ Collective goals can be accomplished mainly by community or groups of people; to have efficient legal rules, it is thus becoming important to understand determinants of group performance vis-à-vis an uncertain future. One example by which legislation's adaptability could be addressed (as a precondition for well-functioning democracy) could be present in collective intelligence as a greater general ability to work together across a wide range of task types, ${ }^{91}$ in an architecture of serendipity, where people are exposed to materials they would not choose, and where people have various experiences, distant from the echo chambers and mechanistic conception of reality towards the holistic one. ${ }^{92}$

Groups perform better when they are cognitively diverse ${ }^{93}$ when members exhibit social sensitivity, the equality in distribution of conversational turn-taking are enabled, and the proportion of females in the group is present. ${ }^{94}$ The last two conditions are in some studies presented as independence among group members. These conditions can be put also in algorithms. Collective relations among people are different than the people per se, as mental phenomena are different from the physical

89 Yoshida, Z. (2010) Nonlinear Science: The Challenge of Complex Systems. Berlin: Springer.

90 Segaran, T. (2007) Programming Collective Intelligence: Building Smart Web 2.0 Applications. Beijing; Sebastapol CA: O’Reilly Media, p. 2.

91 Woolley, A.W. et al. (2010) Evidence for a Collective Intelligence Factor in the Performance of Human Groups. Science, 330 (6004).

92 Sunstein, C.R. (2017) \#Republic: Divided Democracy in the Age of Social Media. Princeton, N.J.: Princeton University Press.

93 Aggarwal, I. \& Woolley, A.W. (2019) Team creativity, cognition, and cognitive style diversity. Management Science, 65 (4); Aggarwal, I. et al. (2019) The impact of cognitive style diversity on implicit learning in teams. Frontiers in psychology, 10 (112).

94 Woolley, A.W. et al. (2010) Evidence for a Collective Intelligence Factor in the Performance of Human Groups. Science, 330 (6004). 
brain, which is the parallel, highly interconnected and not sequential (ifthen) binary and linear system. Results depend on a system's structure; it can give very rudimental, rough conclusions or more complex and sophisticated ones based on a complex nonlinear dynamical system in a higher-dimensional space. Data could be processed in a manner to obtain an independent opinion of all community, but with a twist: public opinion should not follow the majority rule in cases, where a numeric result is not always aligned with objective reality, ${ }^{95}$ but by the statistical or algorithmic extraction of information. A network learning algorithm imitates the human learning process (examples are logic regression, linear regression, decision trees or random forests) which follows a path of possible neighbouring options and their weights until it finds equilibrium between the minimum and maximum efficiency. It thus gradually learns/moves in a complex interactive system given its task, and not just by using symbols and specific rules. Results are hence 'found' and not programmed into the network. Last but not least: it is helpful to check whether a patient has a disease revealed by medical algorithms although their processes are not fully known; the same stands for algorithms that could regulate or at least show future options to decision-makers provided they are doing good for the society.

Hidden structural predispositions are the root causes of inequality. Algorithms consider also structural denominators, which are usually hidden to legislators. One of the classical democratic stances is that without the democratically obtained public opinion rules are just bureaucratic forms of governmentality as the institutionalised use of power through various practices and/or techniques on the population ${ }^{96}$ through which subjects are governed. One could agree that such public opinion could be based

\footnotetext{
95 At one of the EGPA (European Group of Public Administration) conferences in Switzerland, a professor on a stage (sadly I do not remember his name) has told: "the decision could be legal or illegal just like a woman is pregnant or not". At this statement another parable came to my mind: what if, in line with the majority decision-making a child (after a long negotiation, because he would initially say he loves both parents equally), would say he prefers one of the parents by $0.1 \%$ (i.e. $50,1 \%$ vs. $49,9 \%$ ). This would mean that a parent in a minority should be totally ignored and focus should be given only on the former. But this is not true - a child loves almost equally both of his parents. This is not so much about which of the parables is better, but rather as a warning that we should not take them for granted. In this line of thought, common-sense ideas of competitive markets tend to assume that small businesses are an important component of them and that the activities of large businesses which drive out small businesses will make the markets less competitive. Graham, C. (2013) EU and UK Competition Law. New York, London: Pearson Education, p. 6. But lower competitiveness was never recognised as a problem at democratic voting, where the majoritarian "large business" drives out the small one (a minority of voters).

96 Foucault, M. (2004) Naissance de la biopolitique. Paris: Seuil.
} 
on planning as 'the study of resources, future possibilities, and means to be used for attaining the objective call for contributions from all departmental heads within the framework of their mandate, each one brings to this study the contribution of his experience together with recognition of the responsibility which will fall upon him in executing the plan'. ${ }^{97}$ Many such self-evident statements hide their structural predispositions as the basic causes of hidden - and thus unrecognisable - effects.

The persistent structural links among ideological and political arguments are distinct from economic and technological changes, and thus cause the rise of inequality around the world. ${ }^{98}$ Every human society justifies its inequalities; such stance Galtung termed cultural violence (a culture that normalises or sees structural violence and their mechanisms as natural or sine qua non for the development of society) ${ }^{99}$ or Dr Martin Luther King poverty of the spirit. An inequality regime is 'a set of discourses and institutional arrangements intended to justify and structure the economic, social, and political inequalities of a given society' ${ }^{100}$ It is thus not hard to understand why 'power systems inherently fight interfering change... large changes to the social system could mean disturbance to those who benefit disproportionately, along with those in political control' ${ }^{101}$ Advanced algorithms are focused on the larger order influences, intersecting processes and chain reactions, and can expose underlying structural predispositions. Solutions to modern social problems could thus be 'less about the moral aptitude of society and more about how society is technically organised' ${ }^{102}$ Such algorithms can reveal larger-order relations between the political and the property regime that causes socioeconomic inequality. Such 'institutional discrimination' and/or 'systemic racism' caused by the self-interest, competition, free markets, autonomy and dominance, can be revealed by algorithms, even if inequality was not intended and caused by a legislator himself. Algorithms can enforce equality on places, where we think it is already present based on our preexistent predispositions (of formal equality but not of equity or material equality).

97 Fayol, H. (1954) General and Industrial Management. London: Sir Isaac Pitman \& Sons, Ltd., p. 48.

98 Piketty, T. (2020) Capital and Ideology. London: Belknap Press.

99 Galtung, J. (1969) Violence, Peace, and Peace Research. Journal of Peace Research, 6 (3).

100 Piketty, T. (2020) Capital and Ideology. London: Belknap Press, p. 2.

101 Joseph, P. (2017) The New Human Rights Movement. Dallas: BenBella Books, p. 10.

102 Joseph, P. (2017) The New Human Rights Movement. Dallas: BenBella Books, p. xvii. 


\section{CONCLUSION}

Algorithmic governance or administration shows the development of new forms of property that need different democratic controls. Algorithms are typical intangible capital; if they - combine other forms of incomes from the capital - exceed the rate of economic growth of output and income, this will according to Piketty ${ }^{103}$ produce fundamental inequality $r>g$ as the typical destabilising force. On the other hand, they can more easily and transparently show the distribution of wealth in the society (by searching for facts and patterns and the underlying structure that might explain them) and hence inform democratic debate and focus on the right questions. The inequality present in the law similarly happens when rules from the past retain higher (conservative) relevancy then new facts, or when rules reproduce themselves faster than facts emerge. Although algorithms and the law will not fully cooperate for some time it is indisputable that 'refusing to deal with numbers rarely serves the interests of the least welloff' ${ }^{104}$ This should be one of the reasons for public debate on this topic. As long as data on various classes of contemporary society remain beyond the reach of scientific inquiry, equality will be on a loser's side. Algorithmic governance, administration and legislation should become the bubbling and living debate in the public sector, because the private one already uses algorithms on a full scale - and not always in the name of equality or other collective notions.

In reality, no system is perfect. This can be seen in one of the best adaptive and advanced systems, in the immune system that (only within a closed time-period) detects a wide variety of agents (pathogens) and can distinguish them from an organism's cells. Algorithms can receive, evaluate, and adapt quickly to changes than human actions. Algorithms as a computerised set of instructions can be used at general legal rules first as techniques for education and standard recommending/setting devices. The future promises long debates on algorithms and AI. It matters how people think which perspectives they use because they are sooner or later transferred also in the law. When not to use algorithms? Probably when there exists a 'reasonably better alternative design' in terms of legality, riskutility or cost-benefit. Algorithms should prohibit injuries and costs

\footnotetext{
${ }_{103}$ Piketty, T. (2014) Capital in the Twenty-First Century. Cambridge: Harvard University Press.

104 Piketty, T. (2014) Capital in the Twenty-First Century. Cambridge: Harvard University Press, p. 577.
} 
(liability) and enforce legality and innovation without unneeded harm (safety). In the absence of more specific guarantees, the general ones could follow the three 'laws' of robotics developed by Asimov, ${ }^{105}$ paraphrased in three laws of algorithms: 1 . An algorithm may not injure a human being without clearly predetermined legal conditions, or, through inaction, allow a human being to come to harm, without the mentioned conditions. 2 . The algorithm must obey the orders given it by human beings except where such orders would conflict with the First Law. 3. The algorithm can be used as long as such validity does not conflict with the First or Second Law.

Legal acts are still tools for solving a particular problem (although the latter is stated generally, e.g. to reduce alcohol consumption) and they still cannot automatically adapt to their environment without human's/ legislator's intervention. Something could be rotten in legislation; the probability theory and statistics were so far the predominant theories and tools to model uncertainty, while in legal drafts they are usually absent, let alone software modelling of legislation. The anticipative general legal rules are focused on the future. To cope with it, legal norms should be more accommodated to the future's elements than classical binary legislation. This could be done with the known sunset clauses and legal experiments (embedded in legal rules), with adaptive legal norms (different possibilities of action/scenarios used at different thresholds, all pre-enacted by parliament), the emergent strategies, negative scenarios, decisionmaking algorithms and simulations that could serve as inputs without a legal force for the later general legal rules. The latter could advance the results with computable power that makes (practical) experiments with fewer costs, time and negative consequences.

The ability to collect information and the computational power to interpret it now enables substantial collaboration opportunities and a better understanding of many domains. With the advancement of computational power, IT can be helpful for powerful detailed analysis. Deep learning based on algorithms can give new knowledge on data correlations. The law will become intelligent when it will have the calculative and automatic capacity to select/switch among a set of options to the one that will show a higher probability to achieve (go towards) a final goal (a reaction or phase transition from a distant to a closer - to the final goal). The intelligent law would not consider a single optimum

105 Asimov, I. (1991) Robot Visions. New York: New American Library. 
state, but a set of mutually relevant, interdependent states happening in real-life situations. Of course, algorithms are just algorithms: they are not substituting for the human practice, sensitiveness, empathy or compassion; as the helping tools, they cannot listen to problems, to what, how, and what is (not) said; they cannot explain, provide reassurance, and show that one cares, but they can be dynamic, adaptive, flexible and robust. In the beginning, it would be wise to test it as a test simulator (its capacity to cope with rapid changes by switching to intermediate effective rules that would go towards a final goal), simply as a working document, later in a form of a national programme and other documents towards the full legal value of a legal Act. A proposal of 'wait and see' should be thus updated with the Russian proverb of 'trust but verify'. Use of intelligent algorithms should not be dimmed by fear: intelligent software learning is just like any other thing: useful when used appropriately by responsible human officials. It is like fire: it could be used to warm ourselves, or to burn down the city. If a life-threatening human illness is evaluated by algorithms in medicine, where lives are put on stake, then also other human (healthy) conditions could be evaluated similarly. So, the plan of action could be to use algorithms, wait, see, trust and verify. Regarding the second step (i.e. wait), it should be mentioned that on 21 April 2021, the European Commission proposed the first-ever legal framework on $\mathrm{AI}^{106}$ to ensure and improve (among other objectives) the governance and effective enforcement of existing law in relation to the fundamental rights and security requirements applicable to AI systems. The proposal aims to ensure that AI systems placed on the EU market are safe and respect the existing law on fundamental rights and Union values, but it does not mention the use of AI in legislation/regulation per se. Nevertheless, the step towards the use of $\mathrm{AI}$ in law (the protection of human rights) was made.

\footnotetext{
$\overline{106}$ European Commission (2021) Proposal for a Regulation on Artificial Intelligence - Artificial Intelligence Act) and Amending Certain Union Legislative acts \{SEC (2021) 167 final\} $\{S W D(2021) \quad 84$ final $\}$. Available from: https://digitalstrategy.ec.europa.eu/en/library/proposal-regulation-european-approach-artificialintelligence [Accessed 21 April 2020].
} 


\section{LIST OF REFERENCES}

[1] Ackoff, R.L. (1978) The Art of Problem Solving: Accompanied by Ackoff's Fables. New York: John Wiley \& Sons.

[2] Aggarwal, I. \& Woolley, A.W. (2019) Team creativity, cognition, and cognitive style diversity. Management Science, 65 (4), pp. 1455-1947.

[3] Aggarwal, I. et al. (2019) The impact of cognitive style diversity on implicit learning in teams. Frontiers in psychology, 10 (112), pp. 1-11.

[4] Aouadni, I. \& Rebai, A. (2017) Decision support system based on genetic algorithm and multi-criteria satisfaction analysis (MUSA) method for measuring job satisfaction. Annals of Operations Research, 256, pp. 3-20.

[5] Arendt, H. (1972) Crises of the Republic: Lying in Politics, Civil Disobedience on Violence, Thoughts on Politics, and Revolution. New York: Harcourt Brace Jovanovich.

[6] Aristotle, (2007) On Rhetoric: A Theory of Civic Discourse. New York: OUP.

[7] Artosi, A., Pieri, B. \& Sartor, G. (2013) Leibniz: Logico-Philosophical Puzzles in the Law: Philosophical Questions and Perplexing Cases in the Law. Dordrecht: Springer Science \& Business Media.

[8] Ashby, W.R. (1957) An Introduction to Cybernetics. London: Chapman and Hall.

[9] Ashby, W.R. (1960) Design for a Brain: The Origin of Adaptive Behavior. London: Chapman and Hall.

[10] Asimov, I. (1991) Robot Visions. New York: New American Library.

[11] Bar-Siman-Tov, I. (2020) Covid-19 meets politics: the novel coronavirus as a novel challenge for legislatures. The Theory and Practice of Legislation, 8 (1-2), pp. 11-48.

[12] Barnett, J., Soares, A.K. \& Treleaven, P. (2017) Algorithms and the Law. Available from: http://www.jeremybarnett.co.uk/algorithms-and-the-law [Accessed 21 October 2020].

[13] Beer, S. (1959) Cybernetics and Management. London: The English University Press LTD.

[14] Beer, S. (1966) Decision and Control: The Meaning of Operational Research and Management Cybernetics. Chichester: John Wiley \& Sons.

[15] Bentham, J. (1843) The Works of Jeremy Bentham, Principles of Morals and Legislation, Fragment on Government, Civil Code, Penal Law. Edinburgh: William Tait.

[16] Bertalanffy, L.V. (1968) General system theory: foundations, development, applications. New York: George Braziller.

[17] Bingham, T. (2011) The Rule of Law. London: Penguin UK.

[18] Boltanski, L. \& Thévenot, L. (2006) On Justification. Princeton and Oxford: Princeton University Press. 
[19] Bukharov, O.E. \& Bogolyubov, D.P. (2015) Development of a decision support system based on neural networks and a genetic algorithm. Expert Systems with Applications, 42, pp. 6177-6183.

[20] Burstein, F., Brézillon, P. \& Zaslavsky, A. (2010) Supporting Real Time Decision-Making. New York, Dordrecht, Heidelberg, London: Springer Science \& Business Media.

[21] Carnap, R. (1966) Philosophical Foundation of Physics: An Introduction to the Philosophy of Science. New York: Basic Books.

[22] Chang et al. (2021) Mobility network models of COVID-19 explain inequities and inform reopening. Nature, 589, pp. 82-87.

[23] Christian, B. \& Griffiths, T. (2016) Algorithms to Live By: The Computer Science of Human Decisions. New York: Henry Holt and Co.

[24] Cicero, M.T. (1853) The Treatises of M.T. Cicero: On the Nature of the Gods; On Divination; On Fate; On the Republic; On the Laws; and On Standing for the Consulship. London: H. G. Bohn.

[25] Citron, D.K. (2008) Technological Due Process. Washington University Law Review, 85, pp. 1249-1313.

[26] Citron, D.K. (2016) Big Data Should Be Regulated by 'Technological Due Process'. Available from: $\quad$ https://www.nytimes.com/roomfordebate/2014/08/06/is-big-data-spreadinginequality/big-data-should-be-regulated-by-technological-due-process [Accessed 18 June 2020].

[27] D'Amato, A. (1977) Can/Should Computers Replace Judges? Georgia Law Review, 11, pp. 1277-1301.

[28] Dennet, D.C. (2012) Pojasnjena zavest. Ljubljana: Krtina.

[29] Desai, D.D. \& Kroll, J.A. (2017) Trust But Verify: A Guide to Algorithms and the Law. Harvard Journal of Law \& Technology, 31, pp. 1-64.

[30] Dworkin, R. (1978) Taking Rights Seriously. Cambridge: Harvard University Press.

[31] Einstein, A. (1960) Ideas and Opinions. New York: Crown Publishers. Smith, A. (1984) The Theory of Moral Sentiments. Indianapolis: Liberty Fund.

[32] Fayol, H. (1954) General and Industrial Management. London: Sir Isaac Pitman \& Sons, Ltd.

[33] Feltz, B., Crommelinck, M. \& Goujon, P. (2006) Self-organization and Emergence in Life Sciences. London: Springer Science \& Business Media.

[34] Ferrucci, D. et al. (2013) Watson: Beyond Jeopardy! Artificial Intelligence, 199-200, pp. 93-105.

[35] Foucault, M. (2004) Naissance de la biopolitique. Paris: Seuil. 
[36] Fukuyama, F. (2002) Our Posthuman Future - Consequences of the Biotechnology Revolution. New York: Farrar, Strauss and Giroux.

[37] Galtung, J. (1969) Violence, Peace, and Peace Research. Journal of Peace Research, 6 (3), pp. 167-191.

[38] Graham, C. (2013) EU and UK Competition Law. New York, London: Pearson Education.

[39] Grove, W.M. \& Meehl, P.E. (1996) Comparative Efficiency of Informal (Subjective, Impressionistic) and Formal (Mechanical, Algorithmic) Prediction Procedures: The Clinical-Statistical Controversy. Psychology, Public Policy, and Law, 2, pp. 293-323.

[40] Gulick, L. (2003) Notes on the Theory of Organisation. In: Kenneth Thompson, Luther Gulick, Lyndall Urwick (eds.) New York and London: Routledge.

[41] Haeberlen, A., Juznetsov, P. \& Druschel, P. (2007) PeerReview: Practical Accountability for Distributed Systems. ACM SIGOPS Operating Systems Review, 41 (6), pp. 175-188.

[42] Hassan, S. \& De Filipi, P. (2017) The Expansion of Algorithmic Governance: From Code is Law to Law is Code. Field Actions Science Reports, 17, pp. 88-90.

[43] Hubbard, F.P. (2016) Allocating the risk of physical injury from "sophisticated robots": Efficiency, fairness, and innovation. In: RyanCalo, Michael A. Froomkin, Ian Kerr (eds), Robot Law. Cheltenham, Northampton: Edward Elgar Publishing.

[44] Jao, C. (2012) Decision Support Systems. Olajnica: IntechOpen.

[45] Jones, B.D. \& Baumgartner, F.R. (2005) A Model of Choice for Public Policy. Journal of Public Administration Research and Theory, 15 (3), pp. 325-351.

[46] Joseph, P. (2017) The New Human Rights Movement. Dallas: BenBella Books.

[47] Kahneman, D. (2013) Thinking, Fast and Slow. Farrar, Straus and Giroux, New York.

[48] Klir, G.J. \& Elias, D. (2003) Architecture of Systems Problem Solving. New York: Springer Science \& Business Media.

[49] Lahmiri, S. (2016) Prediction of International Stock Markets Based on Hybrid Intelligent Systems. In: Mehdi Khosrow-Pour (ed.) Handbook of Research on Innovations in Information Retrieval, Analysis, and Management. Hershey: IGI Global, pp. 110-124.

[50] Lee, K.-F. (2018) AI Superpowers: China, Silicon Valley, and the New World Order. Boston and New York: Houghton Mifflin Harcourt.

[51] Leibniz, G.W.F.V. (1996) Leibniz: New Essays on Human Understanding. Cambridge: Cambridge University Press.

[52] Lennon, M. (2020) Planning as Justification. Planning Theory E Practice, 21 (5), pp. 803807. 
[53] Martini, M. (2020) Regulating Algorithms: How to Demystify the Alchemy of Code? In: Martin Ebers, Susana Navas (eds) Algorithms and Law. Cambridge: Cambridge University Press.

[54] Meadows, D.H. (2008) Thinking in Systems: A Primer. London: Chelsea Green Publishing.

[55] Meehl, P.E. (2013) Clinical Versus Statistical Prediction: A Theoretical Analysis and a Review of the Evidence. Northvale, N.J.: Echo Point Books \& Media.

[56] Merriam-Webster (2020) Definition of Planning by Merriam-Webster. Available from: https://www.dictionary.com/browse/planning [Accessed 24 October 2020].

[57] Miranda, F. \& Abreu, C. (2016) Handbook of research on computational simulation and modeling in engineering. Hershey: Engineering Science Reference.

[58] Nicolis, G. \& Prigogine, I. (1977) Self-organization in nonequilibrium systems: from dissipative structures to order through fluctuations. London: Wiley.

[59] O'Reilly, T. (2013) Open Data and Algorithmic Regulation. In: Brett Goldstein (ed.) Beyond transparency: open data and the future of civic innovation. Sebastopol, CA: O'Reilly Media, Inc.

[60] Pasquale, F. (2015) The Black Box Society: The Secret Algorithms That Control Money and Information. Cambridge: Harvard University Press.

[61] Piketty, T. (2014) Capital in the Twenty-First Century. Cambridge: Harvard University Press.

[62] Piketty, T. (2020) Capital and Ideology. London: Belknap Press.

[63] Pinker, S. (1997) How the Mind Works. London: Penguin Books.

[64] Poole, D.L. \& Mackworth, A.K. (2010) Artificial Intelligence. Cambridge: Cambridge University Press.

[65] Prigogine, I. \& Stengers, I. (1984) Order Out of Chaos. New York: Bantam Books.

[66] Provost, C., Archer, N., \& Namubiru, L. (2021) Alarm as 2 billion people have parliaments shut or limited by COVID-19. OpenDemocracy. Available from https://www.opendemocracy.net/en/5050/alarm-two-billion-people-have-parliamentssuspended-or-limited-covid-19 [Accessed 28 May 2021].

[67] Reynolds, M. \& Holwell, S. (2010) Systems Approaches to Managing Change: A Practical Guide: A Practical Guide. London: Springer Science \& Business Media.

[68] Rousseau, D. M. (2013) The Oxford Handbook of Evidence-Based Management. Oxford: Oxford University Press.

[69] Rubio, D. \& Lastra, C. (2019) European Tech Insights 2019. Available from: https://docs.ie.edu/cgc/European-Tech-Insights-2019.pdf [Accessed 13 March 2021]. 
[70] Segaran, T. (2007) Programming Collective Intelligence: Building Smart Web 2.0 Applications. Beijing; Sebastapol CA: O'Reilly Media.

[71] Senge, P.M. (2010) The Fifth Discipline: The Art \& Practice of The Learning Organization. New York: Crown Publishing Group.

[72] Simon, H.A. (1996) The Sciences of the Artificial. Cambridge: The MIT Press.

[73] Stasser, G. \& Titus, W. (1985) Pooling of unshared information in group decision making: Biased information sampling during discussion. Journal of Personality and Social Psychology, 48 (6), pp. 1467-1478.

[74] Sunstein, C.R. (2017) \#Republic: Divided Democracy in the Age of Social Media. Princeton, N.J.: Princeton University Press.

[75] The Marshall Project, (2020) Algorithms. Available from: https://www.themarshallproject.org/records/3363-algorithms [Accessed 20 March 2021].

[76] TMF (2019) FDA Approvals for Smart Algorithms in Medicine in One Giant Infographic The Medical Futurist. Available from: https://medicalfuturist.com/fda-approvals-foralgorithms-in-medicine [Accessed 21 September 2020].

[77] Turing, A.M. (1950) Computing Machinery and Intelligence. Mind, 59 (236), pp. 433-460.

[78] Watson, H.J., Rainer, R.K. \& Koh, C.E. (1991) Executive Information Systems: A Framework for Development and a Survey of Current Practices. MIS Quarterly, 15 (1), pp. 13-30.

[79] Watts, D.J. (2011) Everything Is Obvious: *Once You Know the Answer. New York: Crown Publishing Group.

[80] Woolley, A.W. et al. (2010) Evidence for a Collective Intelligence Factor in the Performance of Human Groups. Science, 330 (6004), pp. 686-688.

[81] Yoshida, Z. (2010) Nonlinear Science: The Challenge of Complex Systems. Berlin: Springer.

[82] Zadeh, L.A. (1973) Outline of a new approach to the analysis of complex systems and decision processes. IEEE Transactions on systems, Man, and Cybernetics, 3 (1), pp. 28-44. 